\title{
A novel nicotinoyl peptide, nicotinoyl-LVH, for collagen synthesis enhancement in skin cells
}

\author{
Hyoung Shik Kim ${ }^{1}$ - Seung Hwan Ryu ${ }^{1} \cdot$ Hye In Kim ${ }^{1}$ - Seung Hee Cho $^{1}$. \\ Jeong Hun Lee ${ }^{1} \cdot$ Byung Suk Han $^{2} \cdot$ Kyung Rok Lee ${ }^{2} \cdot$ Sang Hyun Moh $^{1}$
}

Received: 26 April 2016 / Accepted: 7 June 2016 / Published Online: 30 September 2016

(C) The Korean Society for Applied Biological Chemistry 2016

\begin{abstract}
A novel Nicotinoyl fused peptide, Nicotinoyl-LVH, was synthesized by solid phase peptide synthesis method, purified, and tested in cultured skin cells. Nicotinoyl-LVH enhanced the expression level of collagen mRNA and its fragments in fibroblasts. These data show that this novel Nicotinoyl peptide is a promising biomaterial in the anti-aging functional cosmetic market.
\end{abstract}

Keywords Collagen synthesis - Cosmetic active ingredient Nicotinoyl-LVH $\cdot$ Skin cell

\section{Introduction}

Nicotinic acid, which is a common form of B-vitamin niacin, is a derivative of pyridine, with a carboxyl group at the 3-position. It is a precursor of the coenzymes nicotinamide adenine dinucleotide $\left(\mathrm{NAD}^{+}\right)$and nicotinamide adenine dinucleotide phosphate $\left(\mathrm{NADP}^{+}\right)$, which are major coenzymes in vivo. $\mathrm{NAD}^{+}$and $\mathrm{NADP}^{+}$are coenzymes for many dehydrogenases, participating in hydrogen transfer processes, especially ATP synthesis for generating energy (Benavente et al. 2009). Niacin deficiency-induced pellagra is

Sang Hyun Moh $(\bowtie)$

E-mail: biofdnc@gmail.com

${ }^{1}$ Anti-Aging Research Institute of BIO-FD\&C Co., Ltd, Smart Valley A510, 30, Songdomirae-ro, Yeonsu-gu, Incheon 406-840, Republic of Korea

${ }^{2}$ AMI Cosmetic Co., Ltd. 3, 5F Holt B/D, Yanghwa Road 19, Mapo-gu, Seoul 04027, Republic of Korea

This is an Open Access article distributed under the terms of the Creative Commons Attribution Non-Commercial License (http://creativecommons. org/licenses/by-nc/3.0/) which permits unrestricted non-commercial use, distribution, and reproduction in any medium, provided the original work is properly cited. characterized by diarrhea, dermatitis, and dementia. The symptoms of dermatitis are casal collar lesions on the lower neck, hyperpigmentation, thickening of the skin, and inflammation of the mouth and tongue (Ishii and Nishihara 1981; Prakash et al. 2008; Wan et al. 2011). Therefore, this nutrient is used not only as a dietary supplement but also as a skin care and anti-aging product in cosmetic market; its global demand has been rising from 8,500 t/year to 40,000 in recent years (Cantarella et al. 2011).

There are many medical and cosmetic effects of nicotinoyl derivatives, including anti-inflammatory activity (Gieldanowski et al. 1987) and inhibition of melanin production (Kim et al. 2011; Kim et al. 2015), as well as the prevention of HIV infection (Uttekar et al. 2012).

Here, we synthesized a Nicotinoyl derivative, Nicotinoyl-LVH, a novel Nicotinoyl peptide aimed at enhancing the anti-wrinkle effect of the signal peptide. Synthetic peptides have been used in many functional cosmetics because of their defined actions and high stability. These peptides generally show anti-wrinkle effects. We investigated the expression level of biomarkers related to collagen synthesis in skin cell lines. The results showed that Nicotinoyl-LVH is promising anti-aging material because it enhances collagen synthesis.

\section{Materials and Methods}

\section{Synthesis and purification of Nicotinoyl-LVH}

Fmoc-His-OH, Fmoc-Leu-OH, Fmoc-Val-OH, Hydroxybenzotriazole (HOBt), 1, 8-Diazabicyclo[5,4,0]undec-7-ene and Diisoproylcarbodiimide (DIC) were purchased from GLS (Shanghai, China). N,N-Dimethylformamide, Dichloromethane, Trifluoroacetic acid (TFA), acetonitrile and Diethylether were purchased from Daejung (Siheung, Korea). The structural formula of Nicotinoyl-LVH is shown in Fig. 1. 
(A)<smiles>CC(C)CC(NC(=O)c1cccnc1)C(=O)NC(C(=O)NC(Cc1cnc[nH]1)C(=O)O)C(C)C</smiles>

(B)

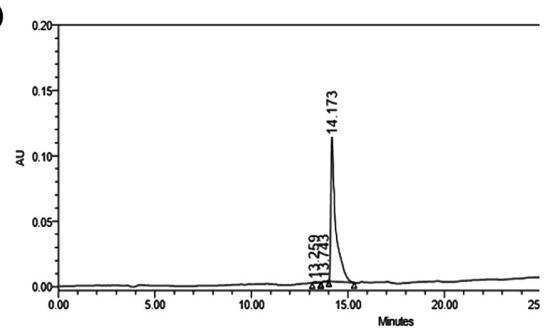

(C)

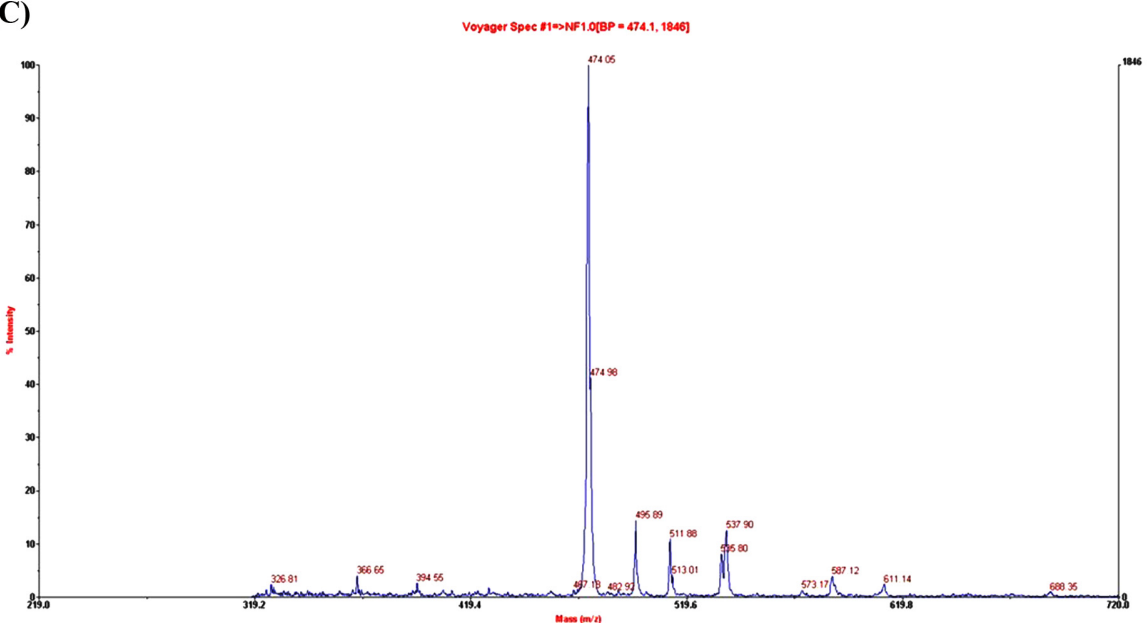

Fig. 1 Structural analysis of Nicotinoyl-LVH. (A) Structural formula of Nicotinoyl-LVH. (B) HPLC data for Nicotinoyl-LVH. (C) LC/MS data for Nicotinoyl-LVH

\section{Structural analysis}

Amino acids and nicotinic acid were coupled with resins by the general HOBt-DIC-mediated solid-phase peptide synthesis protocol (Amblard et al. 2006). After synthesis, sample was purified by reverse-phase high performance liquid chromatography (HPLC) (pump 600E, UV-484 detector, Gemini RP-C18 column 250× $21.2 \mathrm{~mm}$; Waters, Milford, MA, USA) for purification in a gradient of acetonitrile in $0.1 \%$ TFA by using A Shimpack RPC18 column $(250 * 4.6 \mathrm{~mm}$ ID; $5 \mu \mathrm{m}$ particle size; Shimadzu, Kyoto, Japan) for analysis. The elution gradient was 5 to $65 \%$ and flow rate was $1.0 \mathrm{~mL} / \mathrm{min}$ for $30 \mathrm{~min}$. The target peptide peak was analyzed at $230 \mathrm{~nm}$. A Matrix-Assisted Laser Desorption/ Ionization Time-of-Flight Mass Spectrometry assay (MALDITOF-MS) was performed to determine the quality of synthetic Nicotinoyl-LVH using a mass spectrometer (Thermo Fisher Scientific, Waltham, MA, USA).

\section{Cell culture}

Human fibroblast CCD-986sk and Detroit 551 cells were routinely grown in Dulbecco's modified Eagle's medium (DMEM, Hyclone, Logan, UT, USA) containing $10 \%$ fetal bovine serum (FBS) and antibiotic-antimycotic (Thermo Fisher Scientific) at $37^{\circ} \mathrm{C}$ in $5 \%$ $\mathrm{CO}_{2}$.

\section{MTT assay}

MTT assay was performed using the 3-(4,5-dimethylthiazol-2-yl)- 2,5-diphenyltetrazoliumbromide (MTT)-based Cell Viability and Proliferation Kit 1 (Sigma-Aldrich, St. Louis, MO, USA) following the suggested protocol. In brief, $1 \times 10^{5}$ cells were seeded in 96well micro plates and cultured for $24 \mathrm{~h}$. Then the cells were treated with two Nicotinoyl peptides in different concentrations $(0$, $1,5,10,20 \mu \mathrm{M})$ without FBS and incubated for $24 \mathrm{~h}$. The media was replaced with $100 \mu \mathrm{L}$ of MTT solution $(0.5 \mathrm{mg} / \mathrm{mL}$ in DMEM) and incubated at $37^{\circ} \mathrm{C}$ for $4 \mathrm{~h}$. After removing the MTT solution, MTT formazan dissolved in $100 \mu \mathrm{L}$ of dimethyl sulfoxide was added and mixed for $10 \mathrm{~min}$. Absorbance was measured at $540 \mathrm{~nm}$ using a Multiskan TM GO micro plate spectrophotometer (Thermo Fisher Scientific).

\section{Quantitative real-time PCR}

Total RNA isolation, cDNA synthesis, and reverse transcription were conducted using SuperPrep ${ }^{\mathrm{TM}}$ cell lysis \& RT Kit for qPCR (TOYOBO, Osaka, Japan). The target mRNA was procollagen Cendopeptidase enhancer (PCOLCE) and GAPDH was used as the control gene for normalization using QuantiTect ${ }^{\mathbb{R}}$ Primer Assays (Cat no. QT01005725, QT01192646; Qiagen, Venlo, Netherlands). Real-time polymerase chain reaction (PCR) was performed in Rotor-Gene Q system (Qiagen).

\section{Enzyme immunoassay}

The detection of type I procollagen was carried with Procollagen Type I C-Peptide (PIP) EIA Kit (TaKaRa, Kusatsu, Japan) based 
on a sandwich immunoassay method. In brief, $1 \times 10^{5}$ cells were seeded in 48-well microplates and cultured for $24 \mathrm{~h}$. Then cells were treated with two Nicotinoyl peptides in different concentration $(0,1,5,10,20 \mu \mathrm{M})$ without FBS and incubated for $24 \mathrm{~h}$. The amount of PIP was measured from cultured media by measuring the absorbance at $450 \mathrm{~nm}$ using Multiskan TM GO Microplate Spectrophotometer plate reader (Thermo Fisher Scientific). The concentration of PIP was determined by comparing with the standards plotted on a standard curve (Masamune et al. 2013).

\section{Immunofluorescence staining and fluorescence imaging}

For immunofluorescence staining, the following protocol was carried out at room temperature: cells were first washed with PBS and then fixed with $4 \%$ paraformaldehyde (Sigma) for $15 \mathrm{~min}$, followed by three times of washing with PBS. After permeabilization with $0.1 \%$ triton $\mathrm{X}-100$ (Daejung) for $2 \mathrm{~min}$, cells were washed with PBS containing $0.5 \%$ BSA (PBB). After blocking reaction in PBS solution containing $2 \%$ BSA (Bovogen, Victoria, Australia) for $1 \mathrm{~h}$, cells were incubated for $1 \mathrm{~h}$ with anti-ProCOL1A2 antibody (sc-8785, Santa Cruz Biotechnology, Dallas, Texas, USA). Cells were then washed three times with PBB and then incubated with a secondary antibody Alexa488-labeled antigoat IgG (Thermo Fisher Scientific) for $1 \mathrm{~h}$. Finally, cells were again washed three times with PBB and incubated with 4',6diamidino-2-phenylindole (DAPI, Thermo Fisher Scientific) for $10 \mathrm{~min}$. Cells were then washed with PBS and inspected by fluorescent microscope equipped with a CCD camera system (DP30, Olympus, Tokyo, Japan) with Cell-R system (Olympus). This analysis was performed by using image analysis software, ImageJ.

\section{Results and Discussion}

\section{Structural analysis and Cell viability assay}

The structure of synthesized Nicotinoyl-LVH was analyzed by

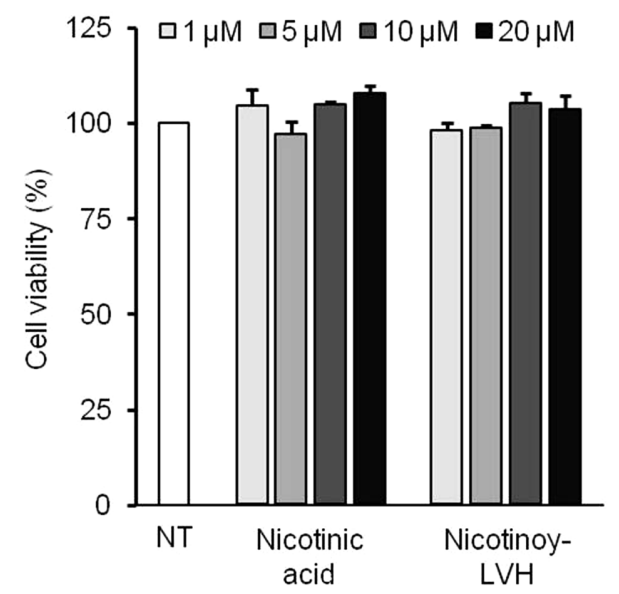

Fig. 2 Cell viability measurement of Nicotinoyl-LVH by MTT assay
HPLC and mass spectroscopy. There was one main peak of Nicotinoyl-LVH in each spectrograph by HPLC (Fig. 1B), and the molecular weight corresponding to Nicotinoyl-LVH was confirmed by MALDI-TOF-MS (Fig. 1C).

Then, we investigated the effect of Nicotinoyl-LVH on cell viability by using the MTT assay in human fibroblast CCD-986sk cells. As shown in Fig. 2, Nicotinoyl-LVH showed no cytotoxicity in the concentration range $1-20 \mu \mathrm{M}$, indicating it does not affect cell viability (Fig. 2).

\section{Collagen synthesis measurement}

Collagen is one of the essential components of extracellular matrix (ECM). The degradation of extracellular collagen induces ECM disorganization and influences dermal moisture and elasticity. Collagens are synthesized as precursor molecules called procollagens. These contain additional peptide sequences, at both the N-terminal and the C-terminal ends (propeptides). To polymerize collagen fibrils at ECM, these propeptides have to cleave off from the collagen (Francini et al. 1993). We estimated the effect of Nicotinoyl-LVH on intra- and extracellular biomarkers related to collagen synthesis. First, we estimated the mRNA
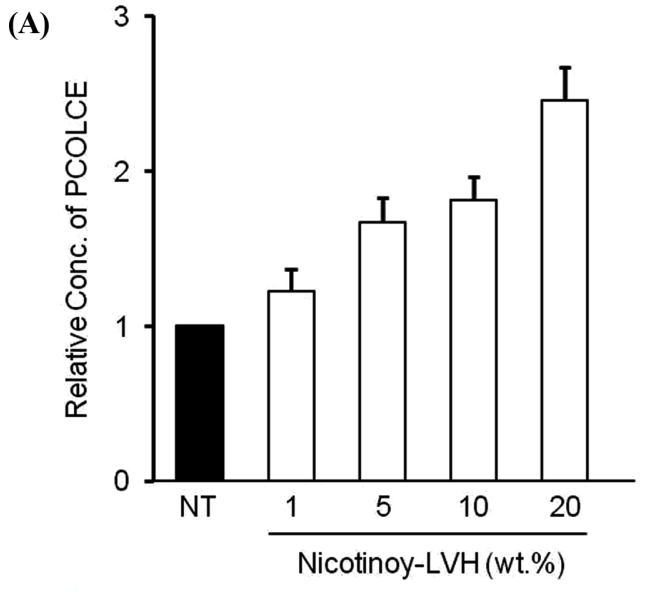

(B)

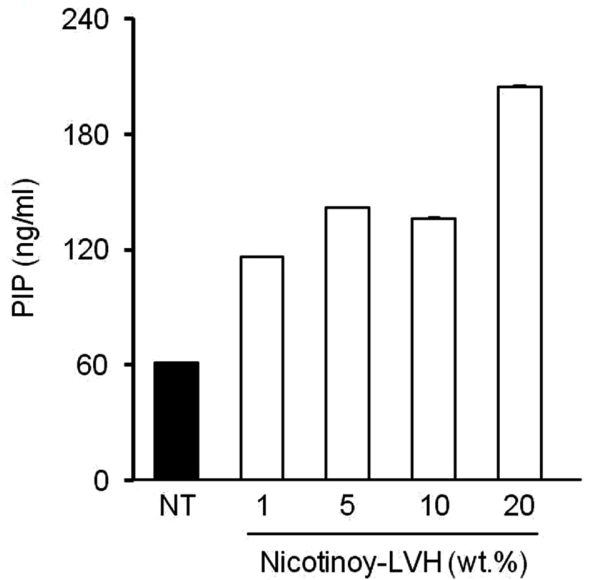

Fig. 3 Measurement of collagen synthesis level after nicotinoyl peptide treatments (A) Intracellular PCOLCE mRNA expression level. (B) Procollagen type I C-peptide level in the extracellular matrix 
(A)

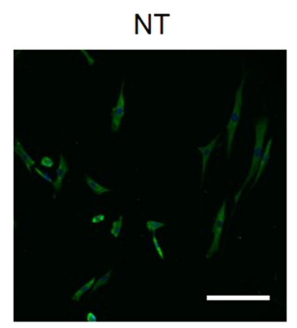

$20 \mu \mathrm{M}$ Nicotinoyl-LVH

(B)

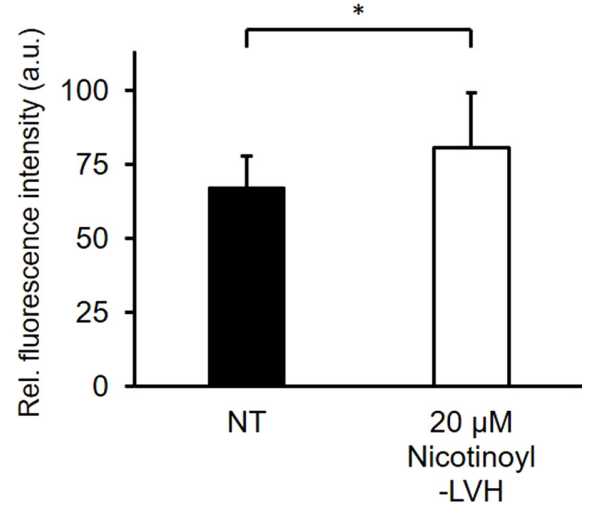

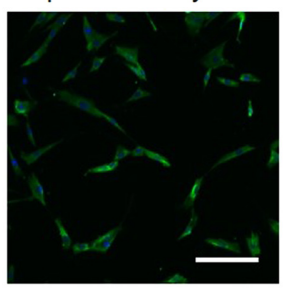

Fig. 4 Procollagen immunostaining in Detroit 551 cells (A) Immunofluorescence staining image of Nicotinoyl-LVH treated and nontreated cells. Scale bars: $10 \mu \mathrm{m}$. (B) Relative fluorescence intensity of individual cell cytoplasm. NT, Nicotinoyl-LVH not-treated. $\left({ }^{*} p<0.05\right)$

expression level of procollagen C-endopeptidase enhancer (PCOLCE). PCOLCE binds to C-peptide of procollagen, and induces its cleavage for collagen polymerization. As shown in Fig. 3A, Nicotinoyl-LVH dose-dependently increased the gene expression of PCOLCE to 2.5 times the maximum in control. We also detected procollagen type I C-peptide (PIP) by an enzyme immunoassay. The amount of free propeptides in media reflected the amount of collagen molecules synthesized. There was also an increase in the amount of procollagen in media, indicating the improvement of collagen synthesis after treatment of NicotinoylLVH (Fig. 3B), as compared with nicotinic acid which did not affect collagen synthesis of fibroblasts.

To estimate the amount of intracellular procollagen directly, we carried out immunostaining of Detroit 551 cells (Fig. 4A). The fluorescence intensity was analyzed to evaluate intracellular procollagen. There was an obviously enhancement of the amount of intracellular procollagen after Nicotinoyl-LVH treatment (Fig. 4B). We also analyzed relative fluorescence intensities of cytoplasm domain. The fluorescence intensities of procollagen in NicotinoylLVH-treated cells were 1.6-fold higher than that in non-treated cells (Fig. 4B). Statistical significance was confirmed by Student's t-test, when comparing fluorescent intensities of Nicotinoyl-LVH-

treated and non-treated cells. These results showed NicotinoylLVH induced procollagen expression in skin cells and enhanced collagen synthesis at ECM.

We synthesized a novel peptide derivative fused to nicotinic acid. Nicotinoyl-LVH did not show cytotoxicity and improved intracellular procollagen synthesis, implying ECM regeneration (Ganceviciene et al. 2012). This result showed that it has antiwrinkle effects in human fibroblasts, which indicates that Nicotinoyl-LVH may be a promising candidate for therapeutic and industrial applications.

Acknowledgments This work was supported by the Technological Innovation R\&D Program (S2178403) funded by the Small and Medium Business Administration (SMBA, Korea).

\section{References}

Benavente CA, Jacobson MK, Jacobson EL (2009) NAD in skin: therapeutic approaches for niacin. Curr Pharm Des 15: 29-38

Cantarella L, Gallifuoco A, Malandra A, Martinkova L, Spera A, Cantarella M (2011) High-yield continuous production of nicotinic acid via nitrile hydratase-amidase cascade reactions using cascade CSMRs. Enzyme Microbial Technology 48: 345-350

Francini G, Gonnelli S, Petrioli R, Bruni S, Marsili S, Aquino A, Camporeale A (1993) Procollagen type I carboxy-terminal propeptide as a marker of osteoblastic bone metastases. Cancer Epidemiol Biomarkers Prev 2: 125-129

Ganceviciene R, Liakou A, Theodoridis A, Makrantonaki E, Zouboulis CC (2012) Skin anti-aging strategies. Dermatoendocrinol 4: 308-319

Gieldanowski J, Kowalczyk-Bronisz SH, Blaszczyk B (1987) Pharmacological investigations on anti-inflammatory activity of tryptamide (3-nicotinoyltryptamine). Pol J Pharmacol Pharm 39: 759-767

Ishii N, Nishihara Y (1981) Pellagra among chronic alcoholics: clinical and pathological study of 20 necropsy cases. J Neurol Neurosurg Psychiatry 44: 209-215

Kim B, Hwang JS, Kim HS (2015) N-Nicotinoyl dopamine inhibits skin pigmentation by suppressing of melanosome transfer. Eur J Pharmacol 769: 250-256

Kim B, Kim JE, Lee SM, Lee SH, Lee JW, Kim MK, Lee JD, Chio KY (2011) N-Nicotinoyl dopamine, a novel niacinamide derivative, retains high antioxidant activity and inhibits skin pigmentation. Exp Dermatol 20: 950-952

Masamune A, Hamada S, Kikuta K, Takikawa T, Miura S, Nakano E, Shimosegawa T (2013) The angiotensin II type I receptor blocker olmesartan inhibits the growth of pancreatic cancer by targeting stellate cell activities in mice. Scand J Gastroenterol 48: 602-609

Prakash R, Gandotra S, Singh LK, Das B, Lakra A (2008) Rapid resolution of delusional parasitosis in pellagra with niacin augmentation therapy. Gen Hosp Psychiatry 30: 581-584

Uttekar MM, Das T, Pawar RS, Bhandari B, Menon V, Nutan, Gupta SK, Bhat SV (2012) Anti-HIV activity of semisynthetic derivatives of andrographolide and computational study of HIV-1 gp120 protein binding. Eur J Med Chem 56: 368-374

Wan P, Moat S, Anstey A (2011) Pellagra: a review with emphasis on photosensitivity. Br J Dermatol 164: 1188-1200 